\title{
La recuperación del patrimonio y el desarrollo del turismo durante el Franquismo. Las intervenciones de la Dirección General de Arquitectura en Úbeda (Jaén)
}

\author{
The recovery of the heritage and the development of \\ tourism during the Francoism. The interventions of the \\ General Direction of Architecture in Úbeda (Jaén) \\ José Manuel ALMANSA MORENO \\ Universidad de Jaén
}

Recibido: 2-IV-2017

Aceptado: 9-VI-2017

RESUMEN: A través de este estudio pretendemos analizar las numerosas intervenciones de gran calado llevadas a cabo en Úbeda (Jaén) entre las décadas de los años 50 y 60 por parte de la Dirección General de Arquitectura, actividad que se vería complementada posteriormente por la Dirección General de Bellas Artes.

Estas actuaciones fueron el resultado del binomio patrimonio-turismo, que vino a recuperar el centro histórico de la ciudad jiennense como símbolo y ejemplo del Renacimiento español, buscando así desarrollar su potencial turístico como pieza clave para mejorar la economía nacional y ofrecer una imagen de modernidad de nuestro país en el extranjero.

Palabras clave: Restauración, Turismo, Franquismo, Úbeda (Jaén), Urbanismo, Arquitectura

ABSTRACT: Through this study we analyze the numerous interventions carried out in Úbeda (Jaén) between the decades of the 50's and 60's by the General Direction of Architecture, activity which would be supplemented subsequently by the General Directorate of Fine Arts.

These performances were the result of the binomial heritage-tourism, who came to restore the historic centre of the city as a symbol and example of the Spanish Renaissance, seeking to develop its tourist potential as key to improving the national economy and provide an image of our country in foreign currency.

Keywords: Restoration, Tourism, Francoism, Úbeda (Jaén), Urbanism, Architecture

Ya antes de finalizar la Guerra Civil, el gobierno del general Franco procedería a la reorganización administrativa del nuevo Estado con el fin de llevar a cabo la reparación de los numerosos daños ocasionados en nuestro patrimonio durante la contienda bélica ${ }^{1}$. De este modo surgirían una serie de

\footnotetext{
${ }^{1}$ El presente artículo se ha elaborado en el marco del proyecto de investigación Los arquitectos restauradores de la España del franquismo. De la continuidad de la ley de 1933 a la recepción de la teoría europea (ref. HAR201568109-P), financiado por el Ministerio de Economía y
} 
organismos para acometer el Plan de Reconstrucción: la Dirección General de Regiones Devastadas (creada por decreto de 31 de enero de 1938, dependiente del Ministerio de Gobernación bajo el mando de José Moreno Torres) y la Dirección General de Arquitectura (surgida por decreto de 23 de septiembre de 1939, siendo responsable de la misma el arquitecto Pedro Muguruza).

En 1957 desaparecería la Dirección General de Regiones Devastadas, creándose el Ministerio de la Vivienda por Decreto-Ley de 25 de febrero. Este Ministerio recogería las funciones del anterior organismo, integrando tres grandes direcciones generales procedentes del Ministerio de Gobernación: el Instituto Nacional de la Vivienda, la Dirección General de Urbanismo y la Dirección General de Arquitectura ${ }^{2}$. Éste último organismo asumiría las funciones de Regiones Devastadas, llevando a cabo las intervenciones más voluminosas y creando su propio servicio de restauración, dirigiendo sus actuaciones hacia los conjuntos históricos ${ }^{3}$.

Las primeras actuaciones de posguerra no afectarían a los centros históricos en cuanto a intervenciones urbanas se refiere, sino que se centraron particularmente en la recuperación de monumentos y edificios de interés (siendo llevadas a cabo por la Dirección General de Bellas Artes y otros organismos locales como serían los ayuntamientos). Superado el período de reconstrucción de postguerra, y gracias al inicio de la recuperación económica y salida del aislamiento internacional, hacia 1958 se comenzarían las intervenciones en los espacios monumentales y simbólicos de los centros históricos, con un cambio importante de planteamientos respecto a su conservación y puesta en valor

Competitividad y los fondos FEDER.

M. PALMA CRESPO, Baeza restaurada. La restauración del patrimonio baezano en el siglo XX, Granada, 2015, p. 220.

A. MUÑOZ COSME, “La documentación de restauración. Significado cultural", en Fuentes documentales para el estudio de la restauración de monumentos en España, Madrid, 1989, p. 13 "que se orientó más a su rentabilidad económica que a su valoración cultural"4.

Sin embargo, desde finales de la década de los '40 ya se aprecian ejemplos orientados a plantear el problema de la recuperación de los centros urbanos. Prueba de ello es la Exposición de proyectos generales de ordenación de las Ciudades Histórico-Artísticas de Toledo, Úbeda, Baeza, Ronda y barrio antiguo de Barcelona, organizada por la Dirección General de Arquitectura en marzo de 1948 en el Círculo de Bellas Artes de Madrid. Con esta exposición, la Dirección General pretendía exponer la labor a realizar en estas ciudades como fase siguiente al estudio de ordenación histórico-artística de estas poblaciones, siendo su intención la de "poner en relieve el problema que este tipo de ciudad planteaba para formar un ambiente adecuado, procurar una ley especial de protección de la ciudad histórico-artística y solicitar del Estado la ayuda económica indispensable". $\mathrm{Y}$ así, gracias a su riqueza y pintoresquismo, se planteó convertir a Úbeda y Baeza en ciudades turísticas por excelencia, ya que ello conllevaría "la mejora de sus conjuntos arquitectónicos, artísticos y pintorescos, saneándolos de todo aquello que desentona y realzando su belleza", puesto que por aquellos años estaban "afectados de una anarquía que rebaja el valor de los mismos debido a que en tiempos anteriores no se experimentó la menor inquietud para la conservación del ambiente estético que siempre ha debido imperar en beneficio de estas ciudades" ${ }^{\prime \prime}$.

En 1949 sería redactado el primer Plan General de Ordenación Urbana de Úbeda (en adelante PGOU) (Fig. 1), realizado por el arquitecto Rodolfo García Pablos por en-

4 M. MARTÍNEZ MONEDERO, "El centro histórico: del olvido de posguerra a la escenografía" en P. GARCÍA CUETOS, E. ALMARCHA NUÑEZHERRADOR y A. HERNANDEZ MARTÍNEZ, Historia, restauración y reconstrucción monumental en la posguerra española, Madrid, 2012, pp. 223-246.

${ }^{5}$ P. PONCE LLAVERO, “Una reunión de urbanistas, una exposición y las ciudades histórico-artísticas de nuestra provincia", Paisaje, marzo 1948, pp. 1261-1262. 


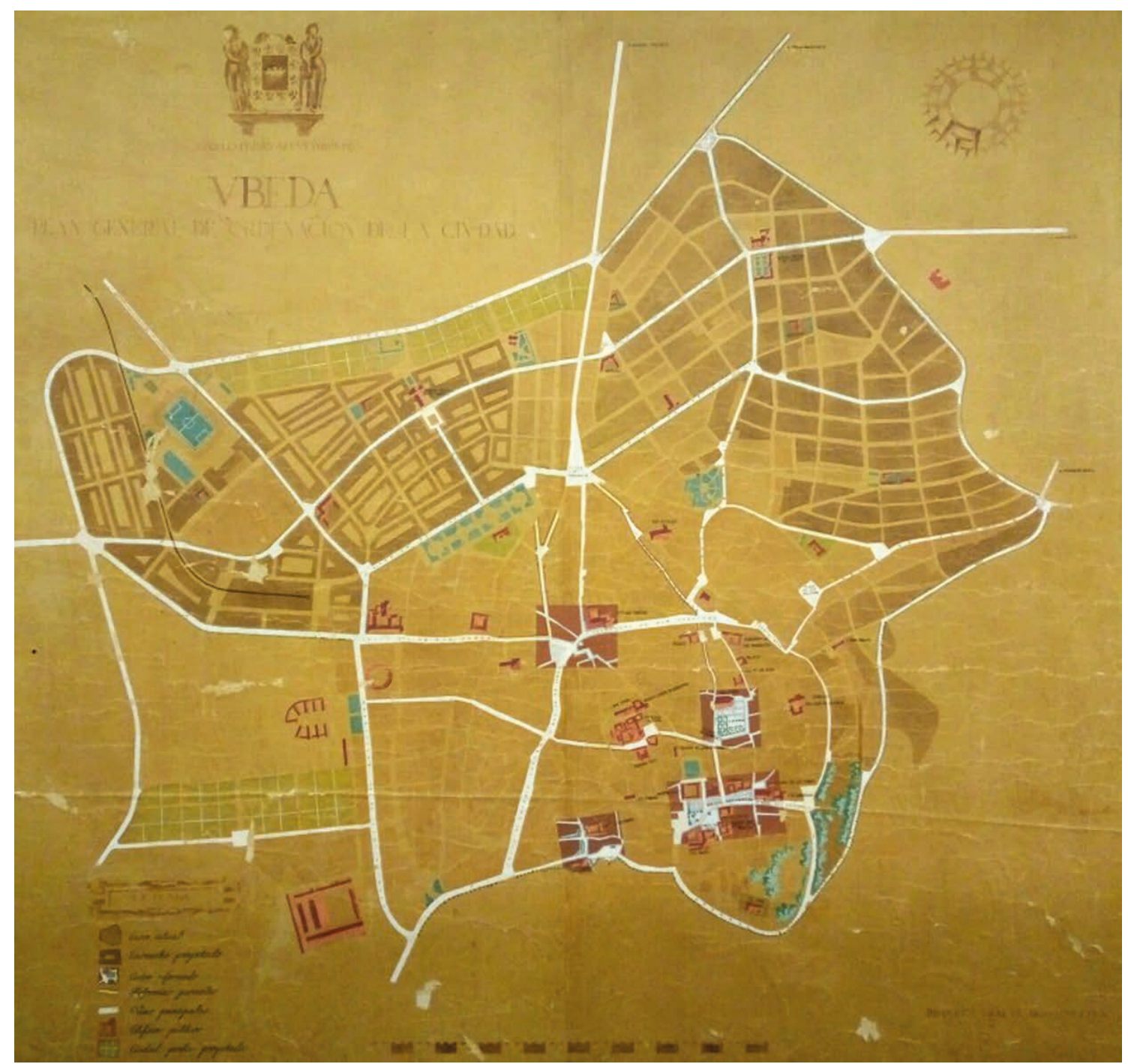

- Fig. 1. Plan General de Ordenación Urbana. 1949. Ayuntamiento de Úbeda. Foto del autor.

cargo del Director General de Arquitectura Francisco Prieto-Moreno Pardo 6 . La aprobación del PGOU se realizó en una fecha temprana, en una época en la que las estructuras administrativas encargadas de la ordenación urbanística de las ciudades españolas aún estaban en proceso de formación. En el mismo se establecían dos objetivos principales de actuación: en primer lugar se planteaba la necesidad de proteger la ciudad, especialmente su recinto histórico-artístico; en segundo lugar, se determinaba el desarrollo urbano de la ciudad mediante el estableci-

\footnotetext{
${ }^{6}$ Archivo Histórico Provincial de Jaén (en adelante AHPJ), Sección de Planeamientos, Legajo 63228.
}

miento de una ordenación racional de sus actividades actuales y de futuro ${ }^{7}$. Pocos años más tarde, la ciudad de Úbeda es declarada Conjunto Monumental por Decreto de 14 de febrero de 1955, con el fin de fomentar la conservación del recinto histórico (si bien, sorprendentemente, en las décadas siguientes se cometerían grandes atentados contra el patrimonio arquitectónico ubetense, como la demolición de numerosas viviendas histó-

${ }^{7}$ L. JUAN MARTÍNEZ, Planeamiento y crecimiento urbanístico de Úbeda durante el Franquismo, Trabajo Fin de Máster dirigido por Ricardo Anguita Cantero y defendido en la Universidad de Granada, Granada, 2014 (inédito). 
ricas y la construcción de grandes edificaciones en el recinto protegido) ${ }^{8}$.

Por su parte, en 1950 se crearía la Sección de Ordenación de Ciudades de Interés Artístico Nacional dentro de la Jefatura Nacional de Urbanismo de la Dirección General de Arquitectura, que se centraría en ensalzar poblaciones relacionadas con la historia de España, especialmente vinculadas con los Reyes Católicos y el descubrimiento de América, como serían Úbeda y Baeza (Jaén), Santa Fe (Granada), Madrigal de las Altas Torres y Arévalo (Ávila), Toledo, Albarracín (Teruel), Sos del Rey Católico (Zaragoza), etc., municipios en donde se desarrolla sobre todo una ordenación urbanística de enfoque turístico9 ${ }^{9}$. Concretamente, la labor se centró "en ordenar, pavimentar y adecentar los entornos de monumentos, ámbitos e itinerarios de Conjuntos que se encontraban en situación lamentable"10. A partir de 1958, la sección de Ordenación de Ciudades de Interés Artístico Nacional realizaría tareas en entornos monumentales continuando con la misión de su predecesora, además de comenzar a realizar obras de restauración. En el caso de Baeza, se realizarían estudios de revitalización del casco histórico de la ciudad (llevados a cabo por el arquitecto Enrique del Castillo Puig), así como la intervención en la Plaza de los Leones y Plaza de Santa María (llevada a cabo bajo la dirección de Rodolfo García Pablos y Francisco Prieto-Moreno) ${ }^{11}$. Por su parte, en el caso de Úbeda, se intervendría en la Plaza Vázquez de Molina y en los Miradores del Salvador (igualmente bajo

${ }^{8}$ R. VAÑÓ SILVESTRE, Protección legal de conjuntos histórico-artísticos. Su aplicación a Úbeda y Baeza, Jaén, 1980.

B. CASTRO FERNÁNDEZ, “Restauración monumental y propaganda: perspectivas de intervención en España y Portugal”, en P. GARCÍA CUETOS, E. ALMARCHA NUÑEZ-HERRADOR y A. HERNANDEZ MARTÍNEZ, Op. cit., p. 166.

10 E. MARTÍNEZ TERCERO, "La recuperación del patrimonio español en la posguerra (1938-1958)", en J. MONJO CARRIÓ (dir.), Teoría e historia de la rehabilitación, Madrid, 1999, p. 121.

${ }^{11}$ M. PALMA CRESPO, Op. cit., pp. 226-244. la dirección de Rodolfo García Pablos en colaboración con los arquitectos Ramiro Moya Blanco y Francisco Pons-Sorolla), así como en otros enclaves monumentales ${ }^{12}$.

Todas estas intervenciones (que se complementarían con las efectuadas por los arquitectos de la Dirección General de Bellas Artes -concretamente por Francisco PrietoMoreno $^{13}$ y José Antonio Llopis Solbes ${ }^{14}$, responsables de la Séptima Zona-) se vinculan al desarrollo que adquiere el turismo por estos años, considerado como el principal motor económico del país. Consciente de su importancia, la Dictadura Franquista controlaría todas sus actividades a través del Ministerio de Información y Turismo (1951-1977), utilizándose el turismo como herramienta de apertura de España al exterior; de este modo, no solamente podría suponer la llegada de capital extranjero, sino que también permitiría consolidar la imagen de una nación en continuo desarrollo y progreso $^{15}$. De este modo, durante estos años

12 El PGOU de 1949 incluía dos planos de gran tamaño a escala 1:2000 (actualmente conservados en el Ayuntamiento de Úbeda), el primero de los cuales muestra la situación urbanística de Úbeda durante las décadas anteriores a la realización del Plan, mientras que el segundo muestra las zonas de ensanche propuestas. En este último plano se proponía la intervención en cuatro zonas importantes del casco antiguo: la Plaza del General Saro (actual Plaza de Andalucía), la Plaza del Generalísimo (actual Plaza 1ํ de Mayo), el Paseo de Vázquez de Molina y la Plaza de San Lorenzo (si bien finalmente no se llevaría a cabo la intervención en todos los enclaves, como a continuación veremos).

${ }^{13} \mathrm{~A}$. ROMERO GALLARDO, "Apuntes y reflexiones en torno a la obra restauradora del arquitecto Francisco Prieto-Moreno y Pardo", E-rph: Revista electrónica de Patrimonio Histórico, no 7, 2010, consultado el 1 de abril de 2017. URL: http://revistaseug.ugr.es/index.php/ erph/article/view/3383

${ }^{14} \mathrm{~J}$. M. ALMANSA MORENO, “La restauración monumental en Úbeda durante los últimos años del franquismo: la obra de José Antonio Llopis Solbes", La Albolafia: Revista de Humanidades y Cultura, no 5, 2015, pp. 71-86, consultado el 1 de abril de 2017. URL: http:// www.albolafia.com/trab/Alb-Doss-005.ALMANSA.pdf

${ }^{15} \mathrm{~J}$. N. TORRES CAMACHO, “Turismo, patrimonio y desarrollo económico a través de las denominaciones geoturísticas en el Franquismo", en Impulso al 


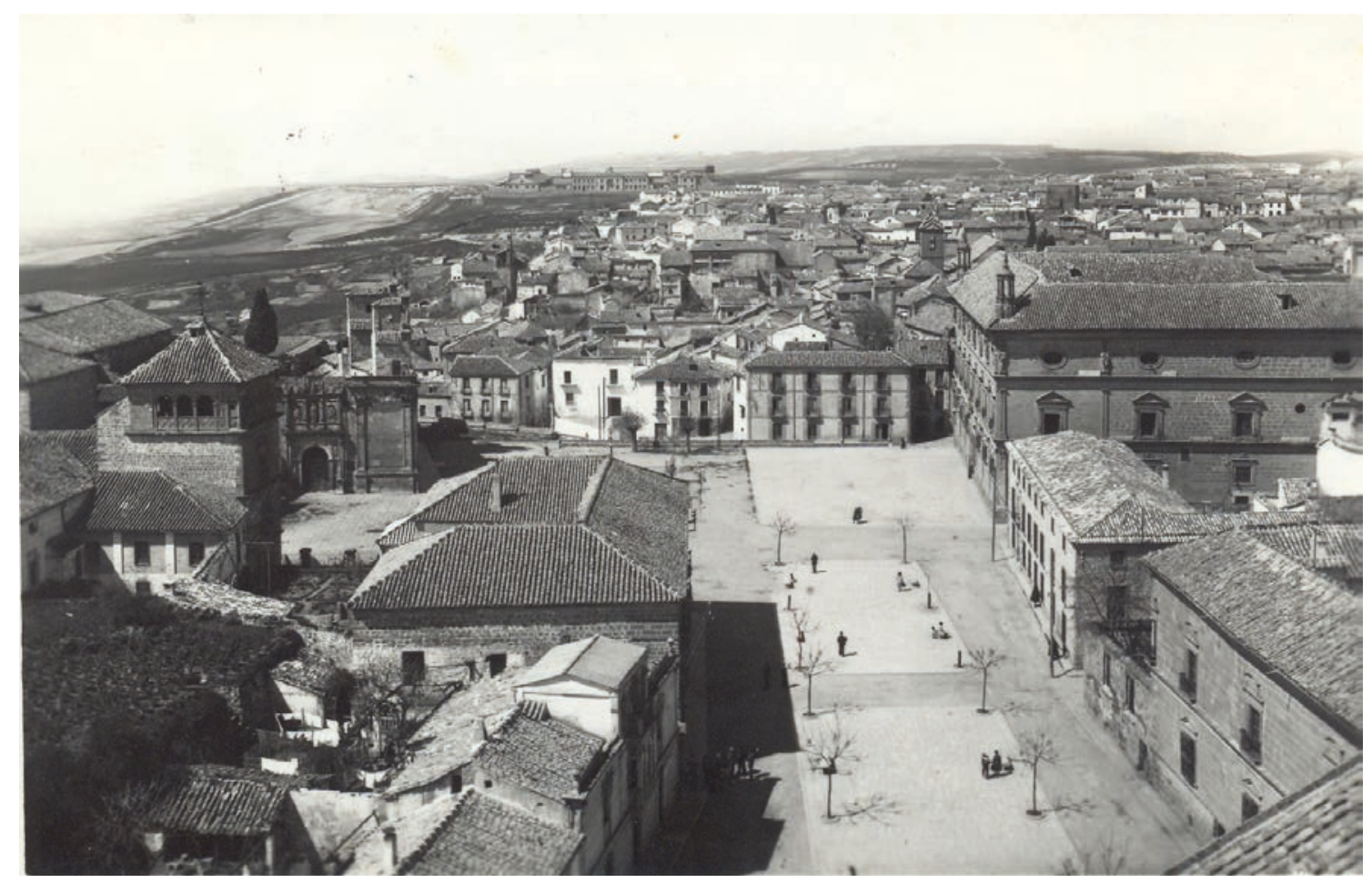

- Fig. 2. Plaza Vázquez de Molina, Úbeda. Hacia 1940. Foto Ediciones Arribas.

se realizarían "intervenciones historicistas, grandilocuentes, folkloristas y ordenaciones escenográficas" en diferentes conjuntos, monumentos y sitios con una marcada tendencia por convertir identidades locales en identidades turísticas, lo cual supondría "la transformación de espacios vivenciales en rutas turísticas, y la homogenización de ofertas que desvirtúan las identidades locales transformándolas en atracciones turístico-culturales"16.

Como resultado de ese binomio turismo-patrimonio se llevaron a cabo numerosas intervenciones en la ciudad de Úbeda, las cuales estaban encaminadas a potenciar el centro histórico de la ciudad jiennense como símbolo y ejemplo del Renacimiento

Desarrollo Económico a través del Turismo. VIII Jornadas de Investigación en Turismo, Sevilla, 2006, p. 262.

16 A. HERNÁNDEZ MARTÍNEZ y B. CASTRO FERNÁNDEZ, "Patrimonio monumental y turismo. La ordenación de conjuntos monumentales en Aragón: el caso de Sos del Rey Católico (Zaragoza)", E-rph: Revista electrónica de Patrimonio Histórico, no 13, 2013, p. 9, consultado el 1 de abril de 2017. URL: http://revistaseug. ugr.es/index.php/erph/article/view/3491 español, sentando las bases de su posterior desarrollo turístico y convirtiéndose en pieza clave para mejorar la economía nacional y ofrecer una imagen de modernidad de nuestro país en el extranjero.

\section{LA PLAZA VÁZQUEZ DE MOLINA}

Considerado como el recinto más monumental de la ciudad, este espacio surgiría a partir de la orden de demolición del alcázar ubetense llevada a cabo por los Reyes Católicos, la cual se hace efectiva en tiempos de la reina Juana de Castilla (1507), empleándose sus piedras para colmatar el colindante valle del arroyo Azacaya. Este lugar era un recinto baldío, denominado originariamente como "Llano de Santa María" por la cercana presencia de la Colegiata de Santa María de los Reales Alcázares (construida sobre la primitiva mezquita aljama de la ciudad). Sin embargo, la construcción de la Sacra Capilla del Salvador (1536-1559), panteón funerario del secretario imperial D. Francisco de los Cobos, así como de otras construcciones residenciales (Palacio del Deán Ortega, Palacio de Vázquez de Molina, Palacio de Man- 
cera...) definirían este espacio como uno de los conjuntos urbanos más importantes del Renacimiento español, conocido durante mucho tiempo como "Llano del Salvador"17.

En 1833 este lugar sufriría una total transformación con la plantación de árboles y jardines, convirtiéndose en un lugar de recreo denominado como "Paseo de las Delicias de la Princesa". Años más tarde, en 1847, se procedería al "arenado de su calle, el derribo del Torreon de tierra frente del Salbador, el arranque de los cerros que le cercan, el ensanche del camino y su nibelacion construccion de asiento y antepechos que faltan"18. Las intervenciones se irían su- cediendo a lo largo de la centuria si bien se trataría de obras de poca envergadura ${ }^{19}$.

El estado de abandono que presentaba la Plaza Vázquez de Molina a mediados del siglo XX demandaba soluciones para salvar su calidad y su ambiente (Fig. 2). Por tal motivo, en 1949 se plantea la ordenación de la plaza, proyecto que se ejecuta entre 19511956 bajo la dirección de Rodolfo García Pablos, Arquitecto Jefe de Ordenación de Ciudades Históricas, contando con la participación del arquitecto Ramiro Moya Blanco. El coste de esta intervención ascendería a 1.101.867' 80 pesetas (Fig. 3) ${ }^{20}$.

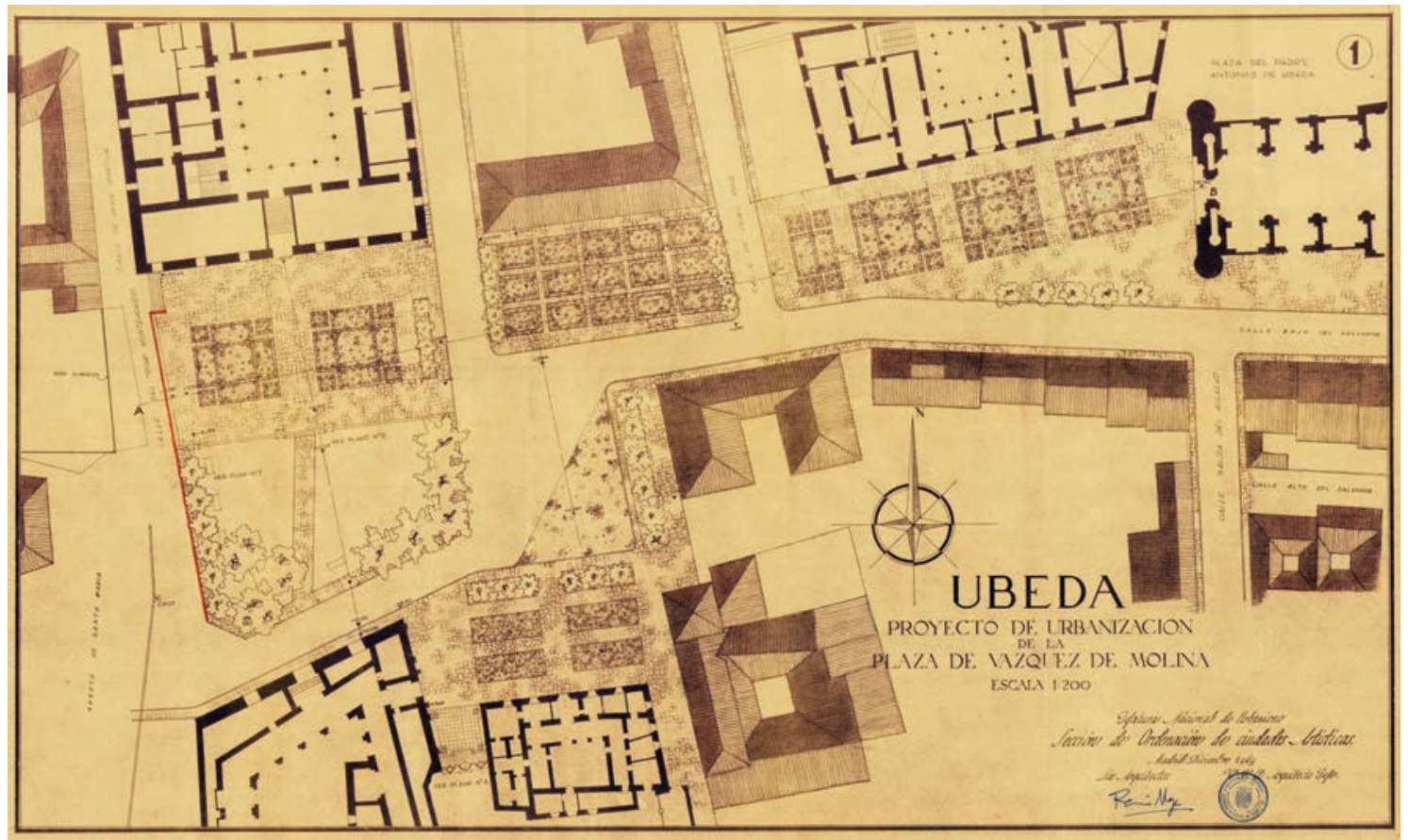

- Fig. 3. Rodolfo García Pablos y Ramiro Moya Blanco. Proyecto de Ordenación de la Plaza Vázquez de Molina. 1949. Ministerio de Educación, Cultura y Deporte. Archivo General de la Administración, Fondo Ministerio de la Vivienda, IDD (04) 117.004, Caja 51/11624.

17 A. MORENO MENDOZA, Úbeda renacentista, Madrid, 1993; ÍDEM, “La Plaza Vázquez de Molina de Úbeda: nuevos datos para el análisis de su configuración urbanística", Espacio, tiempo y forma. Serie VII. Historia del Arte, no15, 2002, pp. 71-94; L. MARÍN DE TERÁN, “Las transformaciones urbanas en Úbeda y Baeza durante el siglo XVI", en Úbeda en el siglo XVI, Úbeda, 2002, pp. 169-188.

18 Archivo Histórico Municipal de Úbeda (en adelante AHMU), Actas de Cabildo, 6-VII-1846, fol. 211v. y 22-I-1847, fol. 319r.

19 J. M. ALMANSA MORENO, "Los espacios públicos en la Úbeda decimonónica", Boletín del Instituto de Estudios Giennenses, no 205, 2012, pp. 163-168.

20 Archivo General de la Administración (en adelante AGA), Fondo Ministerio de la Vivienda, IDD (04)117.004, Caja 51/11624. R. GARCÍA PABLOS y R. MOYA BLANCO, Proyecto de ordenación de la Plaza Vázquez de Molina, Dirección General de Arquitectura, abril de 1949. 
Una de las principales deficiencias que se apreciaban en esta plaza era la "de ser excesivamente grande en relación con los edificios; estos a pesar de su tamaño quedan disimulados y como perdidos sin poderse relacionar entre si de una manera clara y satisfactoria" ${ }^{21}$. Del mismo modo, en el lado Oeste se denunciaba la existencia de viviendas muy pobres que se encontraban a un nivel inferior respecto al resto de la plaza, quedando este lado abierto y contribuyendo así a la sensación de falta de intimidad y proporción de la plaza.

A tenor de la información que ofrece el proyecto, todo parece indicar que el arquitecto no contaría con el correspondiente estudio histórico-artístico de la plaza, pues justifica la gran amplitud de la plaza del siguiente modo: "Es de presumir que antiguamente esta plaza estuviese en dos distintas, por un grupo de pequeñas casas de viviendas hoy derruidas con lo cual los dos ambientes quedarían más proporcionados" 22 ; de hecho, incluso opina que se podría haber construido el Instituto de Previsión (actual Centro de Día para Personas Mayores) dispuesto de forma más adelantada, como solución para repetir la primitiva disposición urbanística. Otra prueba del desconocimiento sobre la historia de este espacio radica en la denominación del Palacio de Mancera como "Palacio de Maucena" (construcción particular de los canónigos de la Colegial, Lope de Molina Valenzuela y Hernando de Herrera).

La ordenación que proponía la Dirección General de Arquitectura consistía en subdividir la plaza en tres ambientes de diferente carácter enlazados entre sí: éstos serían el espacio frente a la Sacra Capilla del Salvador y el Palacio del Deán Ortega (Parador de Turismo "Condestable Dávalos"), otro sería el existente frente al Palacio Vázquez de Molina (Ayuntamiento), y un tercer espacio sería el comprendido entre la parte de la Iglesia de Santa María, la Cárcel del Obispo y

\footnotetext{
${ }^{21}$ Ibídem.

${ }^{22}$ Ibídem.
}

el Palacio de Mancera. Enlazando estos tres ambientes se dispondrían las distintas calzadas, trazadas siguiendo la forma natural de las circulaciones y sin preocupaciones de simetrías aparentes (Fig. 4).

El primer espacio (situado entre la Sacra Capilla del Salvador y el Palacio del Deán Ortega) se proyecta pavimentar con piedra de pequeño tamaño encuadrada por fajas de losa siguiendo el eje marcado por la Capilla. Del mismo modo, para ocultar el grupo de viviendas frente al Palacio, se dispondrían una fila de árboles pequeños pero muy próximos y frondosos que, además, separarían el ambiente de la calzada de circulación.

En relación con el segundo espacio (dispuesto frente al Palacio Vázquez de Molina) se plantea una solución similar, creando una lonja pavimentada con losas de piedra de trazado regular y simétrico en correspondencia con la composición del edificio, reconstruyendo los elementos arquitectónicos que dan nombre al edificio (pilares de piedra unidos con cadenas), así como pedestales con esculturas de leones portando el escudo heráldico de la ciudad; para separar este ambiente se dispondría un cerramiento bajo, a modo de explanada de piedra con bancos. Del mismo modo se plantea cerrar el lado Oeste de la Plaza y tapar las casas del Arroyo de Santa María mediante una cortina de grandes árboles, mezclando especies de hoja caduca y perenne para conseguir este efecto durante todo el año. Dos años después del proyecto inicial, se producirían ligeras variantes que afectarían a este lugar, demoliéndose el muro de contención sobre el Arroyo de Santa María, para ser posteriormente reconstruido en mampostería con chapado en piedra $^{23}$.

El tercer ambiente se proyecta con un carácter menos monumental que los otros dos, con una disposición más libre y pintoresca.

23 Ibídem. R. GARCÍA PABLOS y R. MOYA BLANCO, Proyecto adicional al de urbanización de la Plaza Vázquez de Molina de Úbeda, Jefatura Nacional de Urbanismo - Sección de Ordenación de Ciudades Históricas, noviembre 1951. 


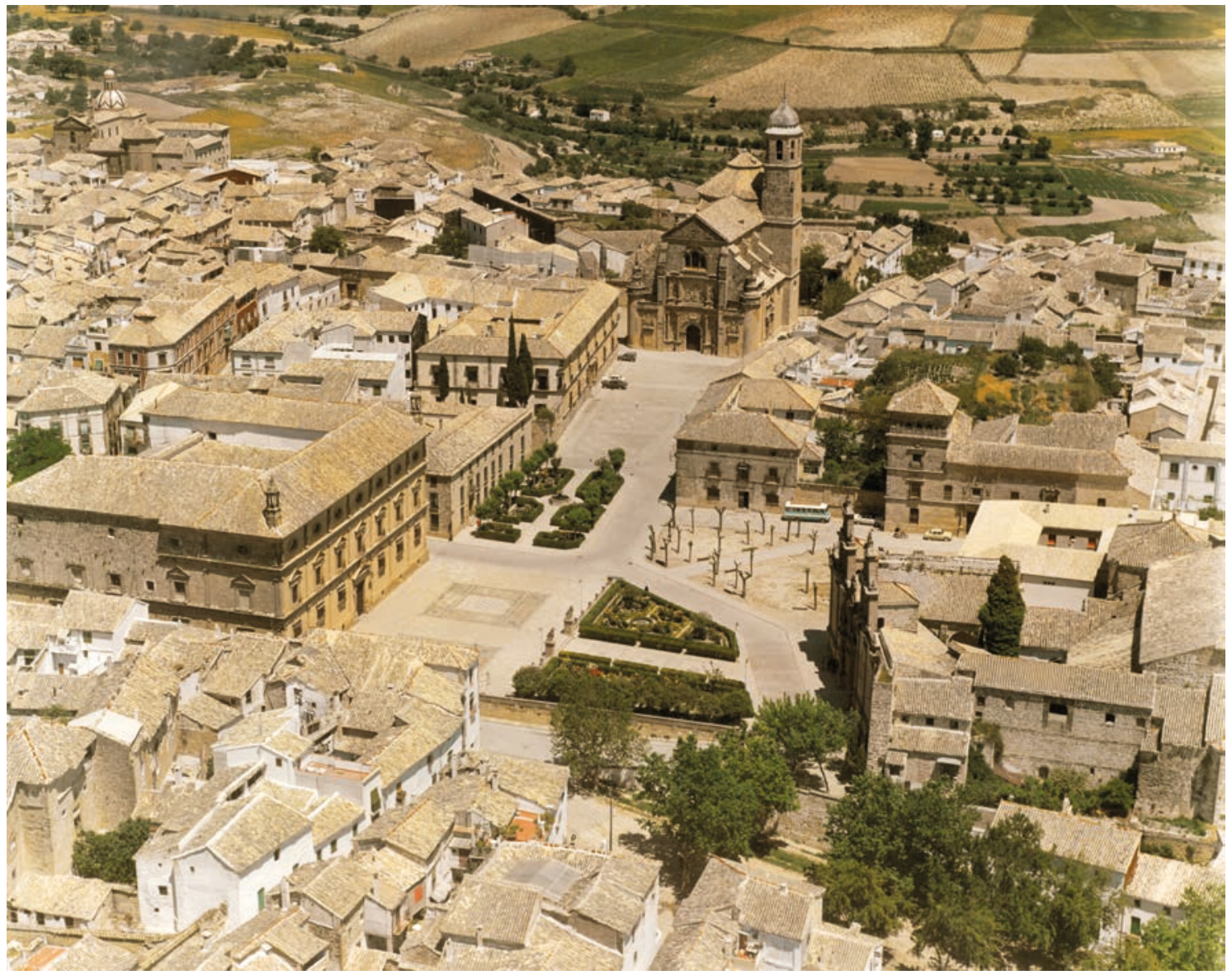

- Fig. 4. Vista aérea de la Plaza Vázquez de Molina. 1967. Foto Baras. Colección particular.

Se realizaría un camino enlosado que conduciría desde el eje del Palacio Vázquez de Molina hasta la puerta principal de la iglesia de Santa María, proyectándose plantar numerosos árboles de gran volumen, ordenados de forma libre y sin rigidez (reemplazados posteriormente por jardines con vegetación de baja altura). Para lograr un carácter popular, el pavimento en esta parte se plantea "de piedra verde en la forma corriente de Úbeda" (que finalmente es sustituido por la técnica del empedrado granadino, incluyendo motivos decorativos a base de cuadrados y estrellas $^{24}$, dejándose parte de este lugar con tierra apisonada).

${ }^{24}$ Además de en este lugar, frente al Palacio Vázquez de Molina se dispondrán igualmente dos grandes escudos heráldicos de la ciudad -con ciertas modificaciones- realizadas con la técnica del empedrado granadino.
Aunque no se indicaba en el proyecto, el punto medio de la plaza (entre el Ayuntamiento y Parador) se trataría con zona de jardín para romper la excesiva longitud del lugar y disimular con su arbolado el edificio que tenía delante -por considerarse de escaso interés-, disponiéndose aquí la fuente del abandonado Palacio de Francisco de los Cobos, interesante pieza de piedra posiblemente procedente de Italia ${ }^{25}$. Esta fuente vendría a sustituir a la antigua fuente pública dispuesta frente a la Casa del Obispo,

${ }^{25}$ Se trata de un pilón octogonal, decorado en cada una de sus caras con composiciones simétricas de grutescos, presentando un vástago central con una taza superior, en cuyo interior están tallados relieves de peces, ranas y serpientes acuáticas. $\mathrm{Al}$ encontrarse mutilada, la fuente sería recrecida en algunas partes mediante cemento, elevándose igualmente de altura el pilar y la taza central (dificultando la visión de los animales acuáticos, tallados para ser vistos a una altura inferior). 
"con estimable aire típico, aunque su valor arquitectónico es nulo, y no parece conveniente conservarla como ornato de una plaza tan monumental"26. Del mismo modo, en los planos del proyecto se puede comprobar la disposición de una fuente monumental adosada al muro existente entre la Cárcel del Obispo y la iglesia de Santa María, espacio que finalmente sería ocupado por la portada de la casa del Regidor D. Luis de Medina, procedente del barrio de San Lorenzo ${ }^{27}$.

Toda la superficie de la plaza fue tratada en sus rasantes, desmontando la curva de terrizo que alteraba la línea de su aspecto y circulación. Respecto a las alineaciones, la única modificación que se planteaba era el ensanchamiento de la calle Juan Ruiz González, considerada como el principal acceso a la Plaza (especialmente pensando en los turistas que se hospedasen en el Parador de Turismo), proyecto que finalmente no se llevaría a cabo. Además de esta se mencionan otras vías de entrada (como la calle Baja del Salvador, que se ejecutaría en una fase posterior), aludiéndose igualmente a la circulación rodada relacionada con varias instituciones locales ubicadas en este lugar (el Ayuntamiento, el Instituto de Previsión y la Caja de Reclutas). Como aspecto anecdótico, mencionar que el arquitecto informa haber tenido muy presente "los itinerarios de las procesiones, que tienen una especial significación e importancia en plaza de Vázquez de Molina"28.

Varios años más tarde, en julio de 1956, se realizaría un nuevo proyecto para mejorar la calle que comunicaba el barrio del Alcázar con la Capilla del Salvador y la Plaza Váz-

${ }^{26}$ J. PASQUAU, "Una fuente monumental”, Revista Vbeda, $\mathrm{n}^{\mathrm{0}}$ 8, agosto 1950, p. 1. La antigua fuente sería trasladada al Arroyo de Santa María, disponiéndose años más tarde en el mismo lugar el monumento al arquitecto Andrés de Vandelvira, obra del escultor José María Palma Burgos (1970).

${ }^{27}$ A. MORENO MENDOZA, Úbeda renacentista..., pp. 104-108.

${ }^{28}$ R. GARCÍA DE PABLOS, “La reforma de la Plaza Vázquez de Molina”, Revista Vbeda, no 4, 1950, p. 9. quez de Molina, cuyo coste total ascendería a 101.481'14 pesetas $^{29}$. El proyecto suponía el desmonte de la rasante del terreno para suavizar la pendiente, para posteriormente proceder a la pavimentación de un tramo de la calle en su proximidad a la plaza, así como el enlosado de una acera lateral a la Sacra Capilla ${ }^{30}$.

Respecto a las edificaciones de la plaza, aparte de algunas restauraciones puntuales en los monumentos (de las que hablaremos después), se indica la conveniencia de reformar el grupo de casas frente al Palacio del Deán Ortega, con el fin de lograr cierta uniformidad y un conjunto discreto. A tenor de los alzados que acompañan el proyecto, observamos la presencia de cinco viviendas, una de las cuales era una construcción posiblemente edificada a principios del siglo $X X$ en estilo ecléctico francés: en esta vivienda se ordena el desmontado del torreón-mirador superior así como el decorado de sus ventanas, procediendo igualmente al picado de la fachada (que se quedaría como un muro de piedra totalmente liso, horadado por varias ventanas $)^{31}$. Igualmente, se ordena el desmontado de la cuarta planta de una de las viviendas, con el fin de buscar una altura similar a la del resto.

Las intervenciones efectuadas en los monumentos fueron ejecutadas por PrietoMoreno, siendo financiadas por la Dirección General de Bellas Artes o por el Ayunta-

29 AGA, Fondo Ministerio de la Vivienda, IDD (04)117.004, caja 51/11810. F. PONS-SOROLLA Y ARNAU, Proyecto de calle de acceso a la Iglesia del Salvador, Dirección General de Arquitectura y Urbanismo Ordenación Ciudades Interés Artístico Nacional, julio 1956.

30 En la pavimentación se buscaría el juego de recuadros formados por adoquines sobre mortero de cemento, cuyos entrepaños van rellenados con firme de morrillo, tal y como se había hecho en la zona entre el Palacio Vázquez de Molina y la Iglesia de Santa María.

${ }^{31}$ Aprovechando esta intervención, la vivienda sería ampliada en extensión, hasta el punto de llegar hasta la pared del antiguo Pósito y construyendo sobre sus cimientos, eliminándose una pequeña callejuela que existía a su lado. 
miento ubetense. Entre las efectuadas por la Dirección General cabría citar las actuaciones -realizadas de modo continuo, en varias fases consecutivas- llevadas a cabo en la Sacra Capilla del Salvador ${ }^{32}$ y en la Iglesia de Santa María de los Reales Alcázares ${ }^{33}$ (generalmente destinadas a solventar problemas en las cubiertas); también se actuaría en la torre del Palacio del Marqués de Mancera (que se encontraba agrietada en gran parte, con el consecuente desplome en los muros y mal estado en algunos sillares), procediéndose al total desmonte de su último cuerpo y posterior reconstrucción ${ }^{34}$.

La intervención en el Palacio Vázquez de Molina sería costeada por el Ayuntamiento. Se procedería a la pavimentación del suelo y a la sustitución de la primitiva escalera por otra nueva de mayor magnificencia, dispuesta en tres tiros (y cuyo coste total ascendería a $134.023^{\prime} 6$ pesetas) $)^{35}$. Según revelan las facturas del Negociado de Obras del Ayuntamiento ${ }^{36}$, fue necesario el labra-

32 AGA, Fondo Ministerio de Cultura, IDD (03)115.000, Caja 26/00279 (Junio 1956) - Caja 26/00158 (Mayo 1958) - Caja 26/00342 (Junio 1959) - Caja 26/00150 (Junio 1960) - Caja 26/ 00352 (Mayo 1965) - Caja 26/00211 (Mayo 1966). F. PRIETO-MORENO, Proyecto de obras de consolidación y restauración de la Iglesia del Salvador de Úbeda (Jaén).

33 AGA, Fondo Ministerio de Cultura, IDD (03)115.000, Caja 26/00359 (Junio 1961) - Caja 26/00249 (Abril 1962) - Caja 26/00389 (Febrero 1964). F. PRIETOMORENO, Proyecto de obras de consolidación y restauración en la Iglesia de Santa María de los Reales Alcázares, de Úbeda (Jaén).

34 AGA, Fondo Ministerio de Cultura, IDD (03)115.000, Caja 26/00279 (Mayo 1955) - Caja 26/00158 (Mayo 1958) - Caja 26/00342 (Junio 1959). F. PRIETOMORENO, Proyecto de obras de consolidación y restauración de la Casa del Marqués de Mancera, en Úbeda (Jaén).

${ }^{35}$ A pesar de que existen facturas y se indican los metros exactos de mármol que se debe comprar para ejecutar la escalera, finalmente se optaría por ubicar aquí la monumental escalera procedente del antiguo Círculo de Artesanos y Unión Ubetense. J. L. LATORRE BONACHERA, Catálogo Exposición Fotográfica "Úbeda, Patrimonio de la Humanidad. Ayer y Hoy", Úbeda, 2007.

36 R. GARCÍA PABLOS y R. MOYA BLANCO, Proyecto de ordenación de la Plaza Vázquez... do de seis arcos, cuatro columnas y quince metros de balaustrada de piedra arenisca similares a los preexistentes en el patio del edificio, empleándose además losas y peldaños de mármol blanco; la escalera se complementaría con el enlucido de las paredes con cemento, así como la creación de una bóveda de yeso. Sobre esta reforma, tenemos la siguiente referencia en la prensa del momento: "Se han hecho en este edificio, y continúan realizándose, interesantes obras de restauración y reforma. En la fachada lateral derecha, cornisa, molduras y pilastras han sido restauradas; la poco antigua y fea escalera del patio, ha sido sustituida por otra de mármol con baranda de piedra imitando el antepecho de la galería, columnas pareadas y arcos almohadillados en el arranque y final, y una bóveda de escayola inspirada en la de la Iglesia de este antiguo convento que está siendo ejecutada por el notable escultor Palma Burgos"37. Además de esta intervención, también se procedería a la pavimentación del salón alto del edificio que se destinaría a Archivo de Protocolos "cuya importancia exige una rápida organización, dada la enorme riqueza de los documentos que en él se guardan" 38 .

Una década después (1964) se instalaría en la planta baja del Ayuntamiento la Oficina de Turismo, siguiendo proyectos de Manuel Sainz de Vicuña ${ }^{39}$. La oficina tendría acceso directo por la Plaza de los Caídos, realizando para tal fin una serie de reformas en la fachada trasera de la misma (en estilo neorrenacentista). En el interior del local se incluirían dos zonas: la correspondiente a la oficina y otra que se destinaría a sala de exposiciones.

37 J. MOLINA HIPÓLITO, “El Palacio del Ayuntamiento de Úbeda", Revista Vbeda, no 1, enero 1950, p. 6.

38 "Hablando con el Alcalde (entrevista a D. Pedro Sola Muñoz)", Revista Vbeda, no 1, enero 1950, pp. 10-11.

39 "Vbeda pregunta. Declaraciones del Sr. Alcalde D. Jerónimo Garvín", Revista Vbeda, no 129, mayo 1964, p. 3. 
Pocos años antes de la intervención en la Plaza Vázquez de Molina, el Emparedamiento de Sancho Íñiguez (popularmente conocida como la Casa del Obispo) habría sido adquirida por el Ayuntamiento -junto con la casa colindante- para proceder a su vaciado y reconstrucción de nueva planta con el fin de instalar en él la Exposición Permanente de Artesanía, Centro Cultural y Oficinas de la Dirección General de Arquitectura para exposición de proyectos de Ordenación y Ensanche de la ciudad, con salas de conferencias, oficinas de urbanismo, etc. ${ }^{40}$. La factura detallada (cuyo coste ascendería a un total de $76.917^{\prime} 45$ pesetas) revela la pérdida de su bello patio mudéjar -que conocemos por fotografías-, incluyéndose partidas destinadas a la demolición de muros y tabiques internos, el desmonte de tres columnas, la demolición de la escalera y de la cubierta ${ }^{41}$.

Aunque se realiza un par de años más tarde (1963), sería necesario hablar también de la ampliación del Parador de Turismo "Condestable Dávalos", que se llevaría a cabo de forma paralela a otra intervención en las cercanías de la plaza (como sería la ordenación de la calle Baja del Salvador y la Redonda de Miradores), en un claro deseo de mejorar el turismo local.

El origen del Parador se encuentra en la visita que realiza el rey Alfonso XIII a Úbeda el 14 de enero de 1926, en la que se hace patente la carestía de establecimientos hoteleros en la ciudad, alojándose el monarca y su séquito en el Palacio del Marqués de la Rambla. Gracias a la intercesión de Dª . Amalia de Orozco y Loring ante el monarca, se plantea la creación de un parador de turismo en la ciudad, siendo alcalde Baltasar Lara. Tras estudiar varias opciones, finalmente se acuerda ubicar el Parador en el Palacio del Deán Ortega (que por aquella época era propiedad de Miguel Fernández de Liencres),

\footnotetext{
40 "Hablando con el Alcalde (entrevista a D. Pedro Sola Muñoz)...", pp. 10-11.

${ }^{41}$ R. GARCÍA PABLOS y R. MOYA BLANCO, Proyecto de ordenación de la Plaza Vázquez...
}

siendo adquirido el inmueble y cedido al Patronato Nacional de Turismo. Las obras de adaptación del inmueble fueron dirigidas por el arquitecto Ricardo Churruca, inaugurándose de forma oficial el 10 de noviembre de 1930 (convirtiéndose en el segundo Parador Nacional de Turismo de España, tras el de Gredos) ${ }^{42}$.

El proyecto de 1963, firmado por el mencionado Manuel Sainz de Vicuña y ejecutado por la Empresa "Copasa" (Constructora de Paradores, S.A.), pretendía ampliar el número de habitaciones para clientes y servicio, mejorando igualmente las zonas del comedor y los salones ${ }^{43}$. La ampliación afectaría especialmente a las zonas del antiguo garaje, elevándose una planta en altura para disponer 29 habitaciones nuevas (aumentando la capacidad del establecimiento hotelero en 70 habitaciones). Del mismo modo se ampliaría el comedor y se dotaría a las cocinas de maquinaria y utillaje nuevo. También se dispondría un salón corrido, una estancia para televisión y un bar, ampliándose el tamaño del garaje para el estacionamiento de un total de 25 coches. La inauguración se llevaría a cabo el 31 de marzo de 1965, ascendiendo el coste del proyecto a 5.800 .000 pesetas $^{44}$.

\section{LA PLAZA DEL GENERAL SARO}

Junto con la Plaza Vázquez de Molina, éste será otro de los espacios que se procederá a urbanizar por estos años. Abierta en los propios límites del recinto medieval amurallado de la urbe, la Plaza de Toledo (también conocida como Plaza de Arriba o Plaza de Comercio) era un importante nudo vial que comunicaba la calle Real con la calle de los Mesones, así como otras dos arterias de

42 AHMU, Plenos, 21-XII-1928, fol. 101r.; 22-IV-1929, fol. 113r.; 25-I-1929, fol. 104r.; 12-XI-1929, fol. 128r.; 25IV-1930, fol. 151v.

43 AGA, Fondo Ministerio de Cultura, IDD (03)115.000, Caja 26/00379. M. SAINZ DE VICUÑA, Proyecto de ampliación del Parador Condestable Davalos en Úbeda, 10 octubre 1963.

44 "De la ciudad. Ampliación del Parador del Condestable", Revista Vbeda, no 134, abril 1965, p. 28. 
la primitiva ronda: la Corredera de San Fernando y el Rastro. Este espacio surgiría en la Baja Edad Media como un espacio abierto frente a la Puerta de Toledo, estando delimitado con soportales -siguiendo el modelo de las rúas castellanas-, y estando presidido por la Torre del Reloj, construida en el siglo $\mathrm{XVI}^{45}$. En este lugar se encontraban igualmente las carnicerías públicas, manteniendo su función como lugar de mercado público hasta la construcción del mercado de abastos en 1932 (Fig. 5).

Durante todo el siglo XIX se producirían numerosas transformaciones en la plaza, siendo la más trascendental la demolición de la Puerta de Toledo. Fueron frecuentes los intentos por parte de los vecinos de eliminar los soportales si bien, finalmente, és- tos se mantuvieron, aunque modificándose en gran medida los alzados de las viviendas. Del mismo modo, a lo largo de la centuria, se situarían en la parte central de la plaza diversas construcciones, estando documentada la presencia de un pabellón de hierro para los bailes o una caseta de cantería (que eran empleados por los comerciantes de la plaza para la venta de sus productos) ${ }^{46}$.

Sería en 1927 cuando este lugar pasa a denominarse Plaza del General Leopoldo Saro, en homenaje a este destacado personaje ubetense quien habría logrado, entre otras cosas, la instalación en Úbeda de las primeras escuelas públicas, el cuartel de sementales, la creación de la estación de tren, etc. ${ }^{47}$. Sin embargo, en tiempos de la II República pasa a ser conocida como Plaza de Adriano

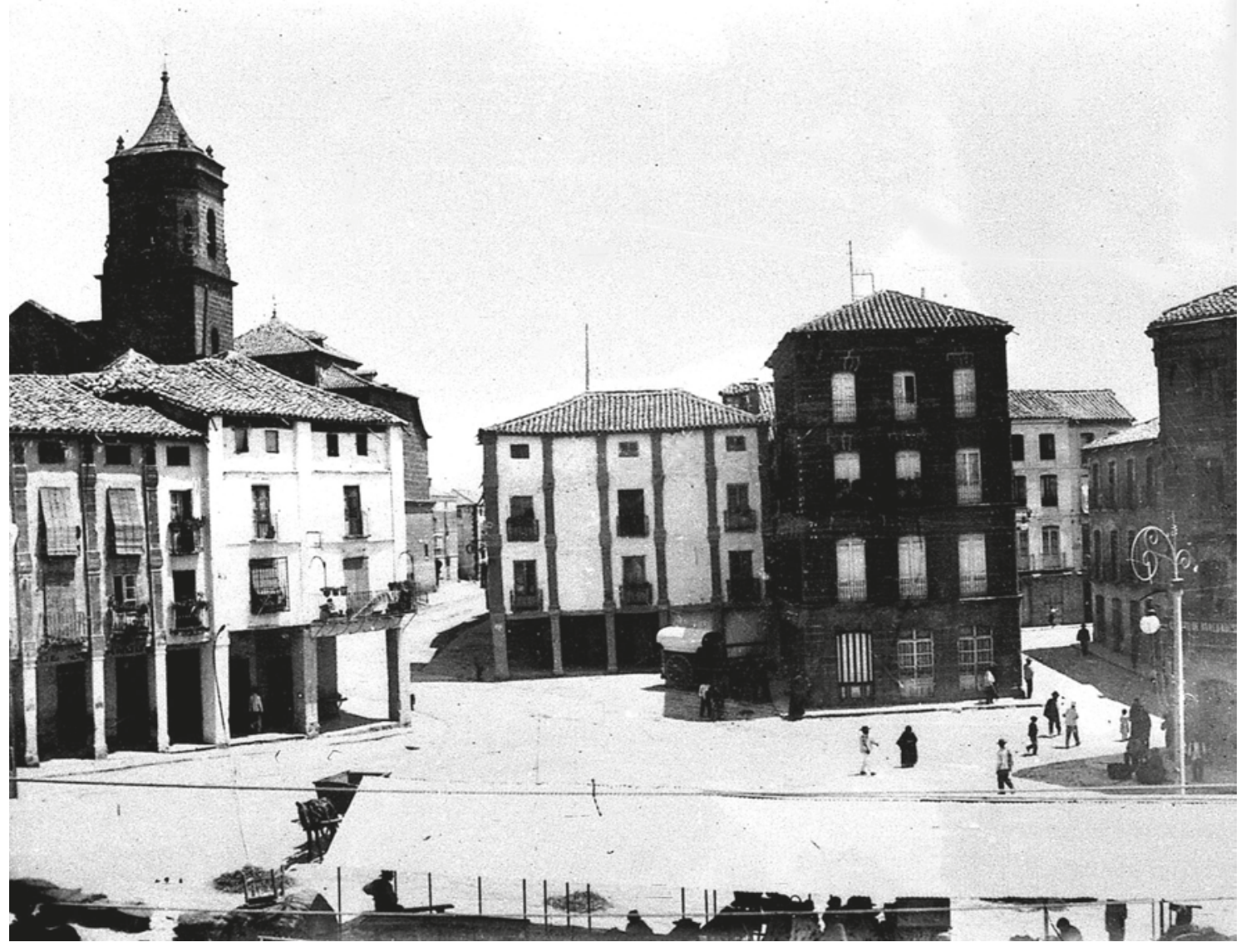

- Fig. 5. Plaza de Toledo. Hacia 1919. Foto cedida por José Luis Latorre Bonachera.

${ }_{45}$ J. R. MARTÍNEZ ELVIRA, "Tramas urbanas y vecindario en la Úbeda del Renacimiento", en Úbeda en el siglo XVI..., p. 206.
${ }_{46}$ J. M. ALMANSA MORENO, "Los espacios públicos en la Úbeda...", pp. 182-199.

${ }^{47}$ En homenaje a este ilustre bienhechor, en 1930 se 


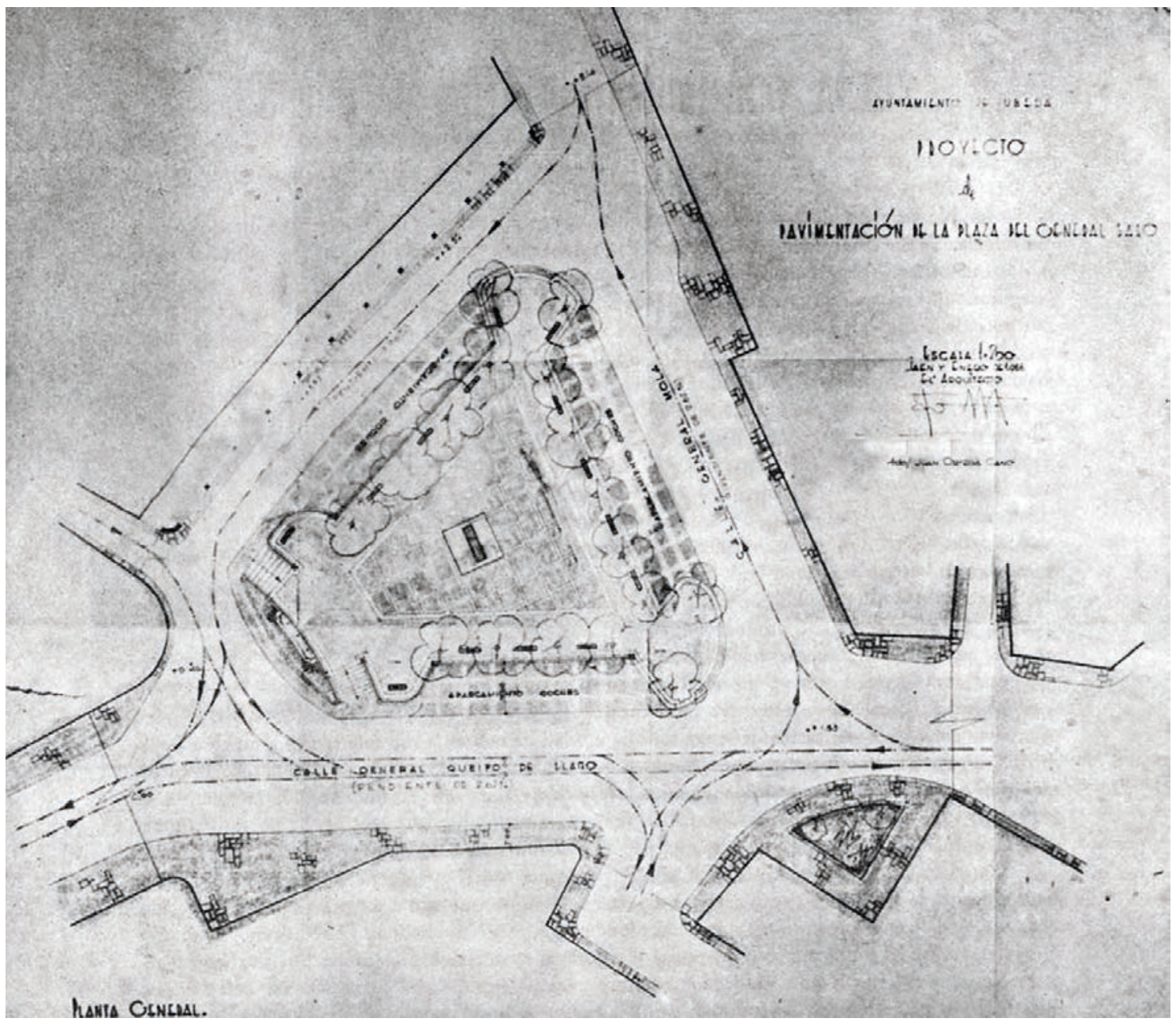

- Fig. 6. Juan Ortega Cano. Proyecto de pavimentación de la Plaza del General Saro. Úbeda. 1956. Revista Vbeda, $\mathrm{n}^{\mathrm{o}}$ 79, julio 1956.

Moreno, recuperando su anterior denominación tras la Guerra Civil.

En el PGOU de 1949 se incluía el proyecto de reformar esta plaza, la cual se llevaría a cabo de forma paralela a la intervención de la Plaza Vázquez de Molina, siendo auspiciada por la Dirección General de Arquitectura pero costeada entre el Ayuntamiento (quien pagaría el 70\% del total) y los vecinos de la plaza (a los que les correspondería el $30 \%$ restante), ascendiendo el importe total a 1.500 .000 pesetas. Si bien tenemos referen-

inaugura una estatua costeada por el Ayuntamiento, la cual permanecería aquí hasta finalizar la Guerra Civil, momento en que es traslada al Paseo del Mercado. AHMU, Plenos, 28-V-1927, fol. 46v.; Actas Comisión Permanente, 6-VII-1927, fol. 80r.; 11-VII-1927, fol. 49v. y 10-X-1928, fol. 32r. cias a este proyecto en marzo de 1955, sería en julio de 1956 cuando se presenta el proyecto, el cual estaría firmado por el arquitecto Juan Ortega Cano, estando asistido por el aparejador municipal Alberto Coronado Martínez (iniciándose las obras en agosto de ese mismo año) (Fig. 6) ${ }^{48}$. No obstante, este espacio ha sufrido numerosas transformaciones a lo largo del tiempo -la última y más radical efectuada en 2002, cuando se llevó a cabo la construcción de un parking subterráneo- por lo que prácticamente nada queda de la remodelación de esta época, pudiéndose hacerse una aproximación a la misma

48 “De la Muy Noble y Muy Leal Ciudad. Preguntas al señor alcalde”, Revista Vbeda, nํ64, abril 1955, p. 8; “El proyecto de urbanización y pavimentación de la Plaza del General Saro", Ibídem, no 79, julio 1956, p. 8. 
gracias a documentos gráficos y testimonios orales (Fig. 7).

Según el proyecto, la plaza tendría en el centro una plataforma elevada con una ligera pendiente y cotas de altura reducida, pavimentada con losas de piedra con recuadros de empedrado rodado sobre capa de arena y cemento. En el centro de la plataforma se dispondría la estatua del General Saro, que volvería al lugar para donde se esculpió (siendo trasladada desde la Plaza del Generalísimo, actualmente denominada Plaza $1^{\circ}$ de Mayo y tradicionalmente conocida como Plaza del Mercado). Cerrando se alinearían unos planteles de jardinería, y el acceso a la misma se resolvería mediante un chaflán de cara a la calle Queipo de Llano (actual Calle
En la plataforma central se dispondrían unas farolas de cerrajería artística, bancos de piedra y árboles de sombra, disponiéndose alrededor de la misma tres zonas de aparcamiento con losetas de asfalto prensadas. Las calzadas limítrofes tendrían una pavimentación de adoquín de granito sobre firme de hormigón, con aceras de losa de piedra, igualmente asentadas.

En las cercanías de la plaza y confluyendo con la calle Corredera de San Fernando existía un rincón triangular junto a la "Tienda del Paso" (vivienda decimonónica construida en el lugar donde se situaba la Puerta de Toledo, de doble acceso entre la Plaza y la calle Real -de donde deriva su popular nombre-) en donde se planteaba disponer

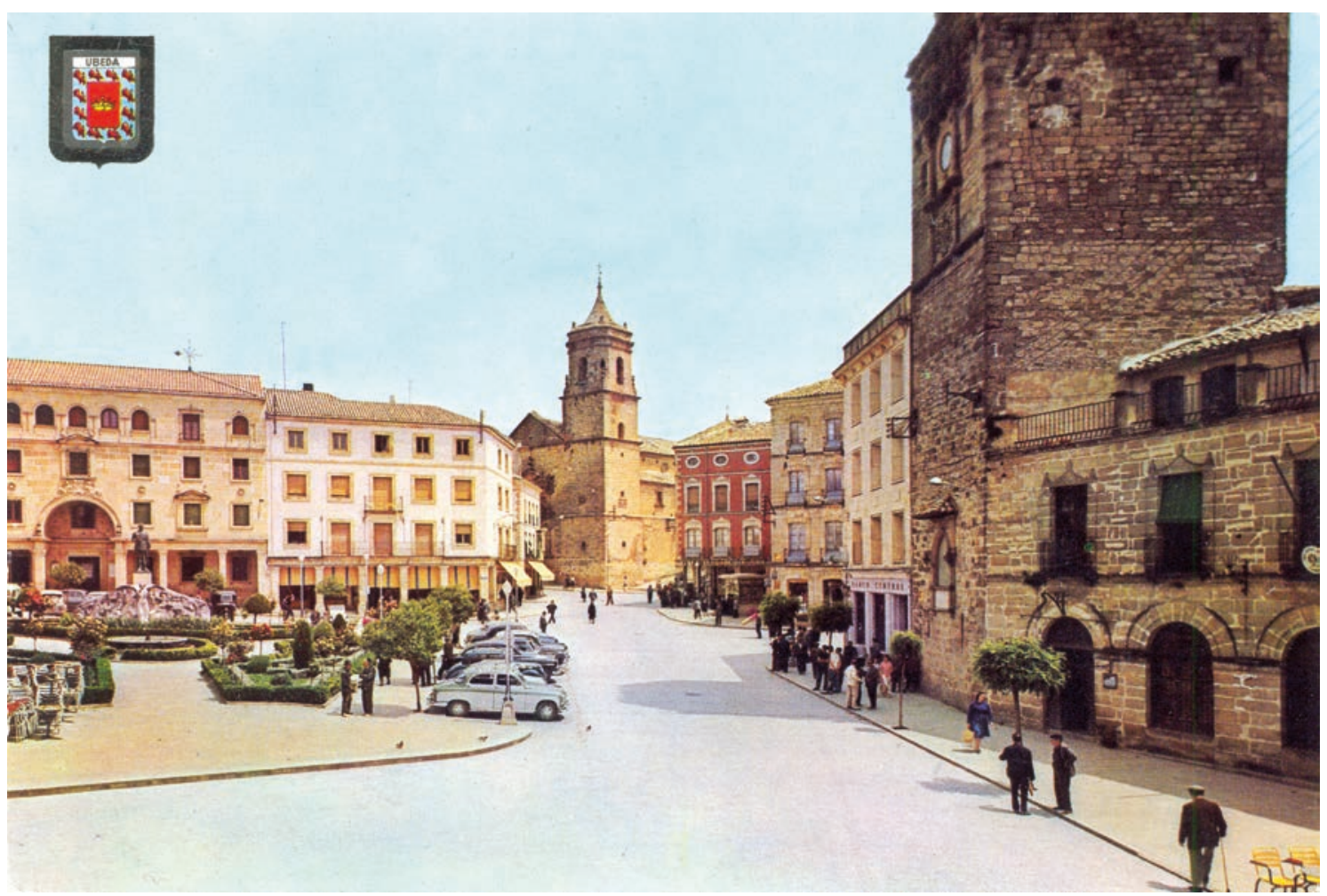

- Fig. 7. Plaza del General Saro. Hacia 1963. Foto Escudo de Oro.

Rastro), con escaleras laterales y una fuente artística en su parte frontal (que nunca se llegaría a realizar $)^{49}$.

49 En lugar de la fuente proyectada en la parte inferior de la plaza, se dispondría en la parte central de la misma una fuente taza de poca altura rodeada de vegetación, tal y como se puede apreciar en las postales otra zona de jardinería, que finalmente no se

editadas hacia 1965. Un par de décadas más tarde, el monumento del General Saro serviría como base para la fuente, funcionando como tal hasta su eliminación en la intervención de 2000-2002 (y volviéndose a recuperar en 2007). Para más información: M. MADRID DELGADO, "La estatua fusilada", Ideal, 10-IV-2010, p. 18. 

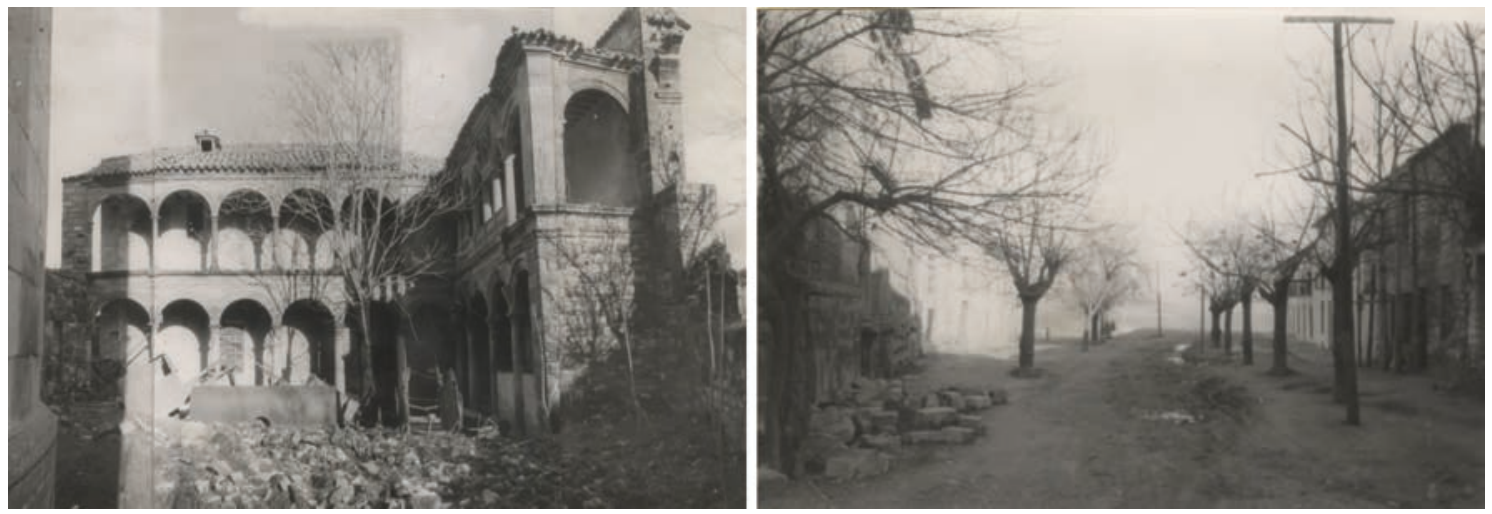

- Fig. 8. Hospital de los Ancianos del Salvador y calle Baja del Salvador. 1963. Ministerio de Educación, Cultura y Deporte. Archivo General de la Administración, Fondo Ministerio de la Vivienda, IDD (04)117.004, Caja 51/11810.

llevaría a cabo (ocupándose posteriormente con un kiosco de prensa).

\section{LOS MIRADORES DEL SALVADOR}

De forma paralela a la mencionada ampliación del Parador, en octubre de 1963 se proyecta una nueva intervención como complemento a la realizada anteriormente en la Plaza Vázquez de Molina (igualmente bajo la dirección de Rodolfo García Pablos, contando con la colaboración de los arquitectos Ramiro Moya Blanco y Francisco PonsSorolla Arnau). Con ella se pretendía actuar en la calle Baja del Salvador, con el fin de conectar la plaza con los caminos de ronda de la ciudad y los accesos por la zona Sur (y cuyo importe total ascendería a 1.957.571'88 pesetas) ${ }^{50}$.

Esta calle presentaba un carácter puramente residencial de tipo modesto, no existiendo construcciones relevantes -excepto la Sacra Capilla del Salvador y el Hospital de los Ancianos del Salvador-, disponiéndose viviendas de dos y tres plantas "sin ningún valor artístico ni pintoresco pero que forma un conjunto discreto y agradable, a lo que

${ }^{50}$ AGA, Fondo Ministerio de la Vivienda, IDD (04)117.004, Caja 51/11810. R. GARCÍA PABLOS, F. PONS-SOROLLA Y ARNAU y R. MOYA BLANCO, Úbeda (Jaén). Ordenación del Mirador de El Salvador, Dirección General de Arquitectura - Ordenación de Ciudades de Interés Artístico Nacional, octubre 1963. contribuye una doble fila de árboles de buen porte" 51 (Fig. 8).

La calle remataba en un mirador, destacando por su enorme valor paisajístico al abrirse al valle del Guadalquivir. A pesar de ello este lugar presentaba un aspecto deplorable, apareciendo edificaciones suburbiales dispuestas de forma anárquica, vertederos de escombros y basura, etc.; del mismo modo, el mirador se conformaba mediante un muro de contención que se encontraba muy deteriorado. Por su parte, el patio del Hospital de los Ancianos estaba separado de la calle por un muro bajo de piedra, que dificultaba su contemplación desde el exterior; a pesar de presentar una buena conservación estructural, el interior presentaba un lamentable estado de abandono y suciedad al usarse como almacén.

El proyecto se plantearía en tres ámbitos diferenciados, como serían el Hospital de los Venerables Ancianos, la calle Baja del Salvador y el mirador (Fig. 9).

En primer lugar, en el antiguo hospital se procedería a realizar algunas obras de saneamiento y restauración de la arquitectura, para proceder posteriormente al desescombro y a la limpieza total del patio; tras esto, se plantarían árboles y arbustos, formando un pequeño jardín al interior. Del mismo modo, se procedería a consolidar el extremo

\footnotetext{
${ }^{51}$ Ibídem.
} 


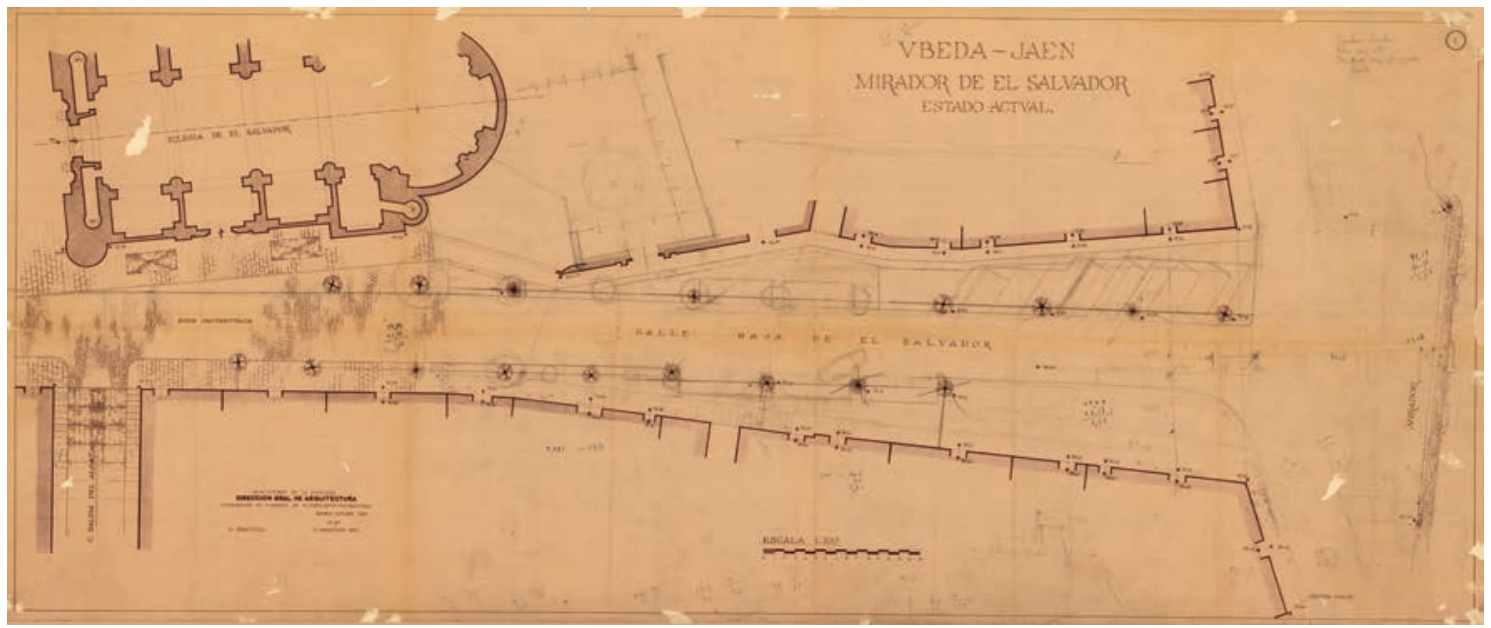

- Fig. 9. Rodolfo García Pablos, Francisco Pons-Sorolla y Ramiro Moya Blanco. Ordenación del Mirador de El Salvador, Úbeda - Jaén. 1963. Ministerio de Educación, Cultura y Deporte. Archivo General de la Administración, Fondo Ministerio de la Vivienda, IDD (04)117.004, Caja 51/11810.

de la fachada a la calle pero manteniendo el aspecto del claustro en ruina, debido a su propia belleza así como por el hecho de no ser fácil conjeturar cual sería la disposición que tuvo originalmente ${ }^{52}$. Respecto al cerramiento del claustro, se demolería el muro existente y se sustituiría con una verja de hierro sobre zócalo bajo de piedra (aprovechando la piedra del muro demolido); del mismo modo se cambiaría la disposición en planta del muro, liberando asimismo el ábside del Salvador y formando un rincón para el reposo y la contemplación de las ruinas del claustro. Años más tarde, todo el edificio sería intervenido por Llopis Solbes ${ }^{53}$.

El segundo campo de actuación se centraría en la calle Baja del Salvador, en la que se procedería a su pavimentación (siguiendo

52 Sabemos que en 1918, a propuesta del concejal Bajo Delgado, se acordaría "la demolición de la fachada y galerias del patio del antiguo Asilo de Ancianos del Salvador, y que con las piedras procedentes del derribo, se reconstituyan las referidas fachada y patio, edificandolas sobre los nuevos terrenos destinados á la ampliación del Cementerio". Por desgracia, nada queda de esta intervención en el actual cementerio. Para más información: J. M. ALMANSA MORENO, “Hospitales y centros de beneficencia en la Úbeda decimonónica", Ilustración y libertades: revista de pensamiento e historia de las ideas, $\mathrm{n}^{\mathrm{0}}$ 2, 2011, pp. 99-100.

53 ÍDEM, "La restauración monumental en Úbeda...", pp. 71-86. el adoquinado ya iniciado en la calzada de vehículos). También se enlosarían las aceras continuando el proyecto previo hasta la fachada del Hospital como parte más noble, mientras que en el resto de la calle se emplearía una disposición más popular y económica, pavimentando con enmorrillado o empedrado granadino entre fajas de piedra. Las citadas fajas estarían separadas de la calzada adoquinada mediante bordillos, pavimentándose simplemente con tierra apisonada, permitiendo el libre aparcamiento de automóviles (especialmente pensado para el cercano Parador de Turismo y los visitantes al Mirador). En relación al arbolado, se conservaría el existente y se ampliaría en la medida de lo posible.

La última parte de la actuación afectaría al mirador en sí, realizando uno nuevo en el lugar donde se encontraba el anterior, muy simple pero dignamente ejecutado y relacionado con la futura red viaria de esa zona; del mismo modo se procedería previamente a la limpieza y plantación de árboles y arbustos adecuados al clima en la zona de la ladera.

El mirador se plantea como un morro de contención con planta ligeramente cóncava con contrafuertes en los extremos para subrayar la forma de la vaguada, construido delante del existente y quedando ambos trabajos unidos sólidamente y con la adecuada 
cimentación; se realizaría en mampostería trasdosada de hormigón en masa, con paramentos encalados. La meseta del mirador se cerraría en su frente por un antepecho alto de gran anchura, con el fin de encauzar la vista hacia el paisaje lejano e impedir la visión de la parte baja, cerrándose lateralmente por dos bancos corridos con respaldo de piedra. El pavimento se realizaría de morrillo entre fajas de piedra, disponiendo en el centro un pequeño aparcamiento para coches.

La construcción de este mirador fue relativamente económica, al conservarse el muro preexistente que, aunque deteriorado y poco estático, no presentaba fallos importantes estructurales; del mismo modo, los paramentos exteriores eran simplemente de mampostería encalada.

Aunque no se menciona en el proyecto, sí que encontramos en los planos el diseño de la fuente de piedra (de dos caños) que se dispondría en la Plaza de Santa Lucía, cerca-

\section{LA IGLESIA DE SAN PEDRO}

Las Hermanas Carmelitas de la Caridad de Úbeda llegarían a Úbeda en 1904, asentándose en un primer momento en una vivienda decimonónica en la calle Antonio Medina $\mathrm{n}^{\mathrm{o}} 1$ (propiedad de $\mathrm{D}^{\mathrm{a}}$. Natividad Ordoñez, viuda de Iturralde), y pasando dos años más tarde al cercano Palacio de Conde de Guadiana (primitiva vivienda de D. Antonio de Ortega y Porcel, construida entre 1611-1615). Las religiosas se alojarían en el palacio, lugar en donde también tenían la residencia y colegio para las niñas, empleando la colindante iglesia de San Pedro como capilla privada (Fig. 10) ${ }^{54}$.

En 1926, la superiora Sor Josefa Bayona solicita la cesión del rincón formado entre la puerta del colegio y la iglesia de San Pedro "para cerrarlo con una pared y una verja y hacer jardín en evitación de que no se depositen basuras ni arrojen animales muertos" ${ }^{\prime \prime 5}$, algo a lo que el cabildo no accede. Sin embar-

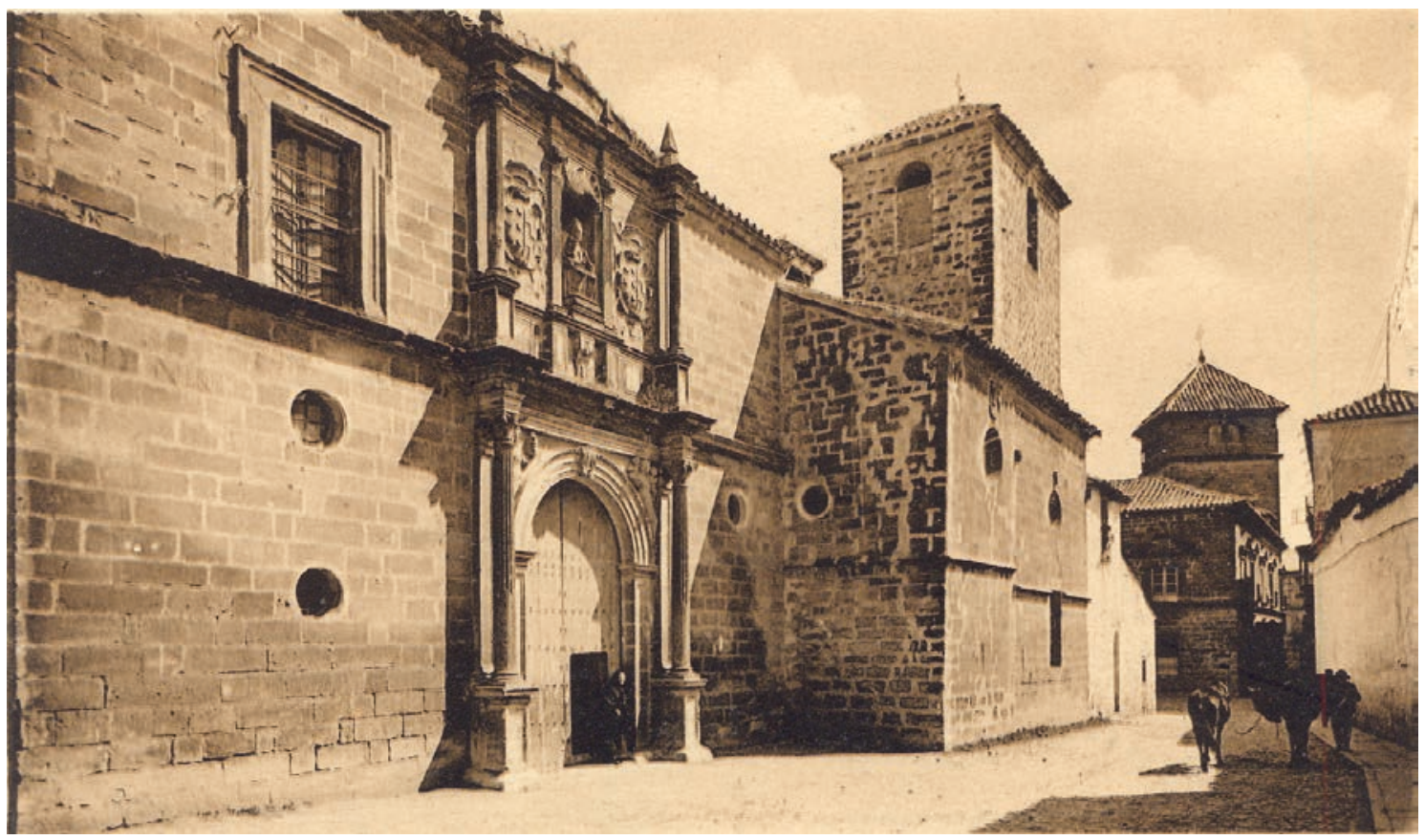

- Fig. 10. Luciano Roisin. Iglesia de San Pedro. Úbeda. Hacia 1930. Foto cedida por José Luis Latorre Bonachera.

no al mirador. Décadas más tarde se dispondría la monumental farola de forja de cuatro brazos que preside este lugar.
${ }^{54}$ R. MOLINA NAVARRETE, “Datos históricos del Colegio de las HH. Carmelitas de la Caridad de Úbeda", Revista Ibiut, no 44-45, 1989, pp. 26-27.

${ }^{55}$ AHMU, Plenos, 10-II-1926, fol. 107r. 
go, en 1944 se vuelve a insistir en este proyecto acordándose que antes de proceder a la concesión del proyecto "presenten un diseño del cerramiento en el que tendrá en cuenta la armonía a guardar con el estilo arquitectónico de los edificios que comprende ${ }^{\prime \prime 56}$; a pesar de que en esta ocasión se vuelve a acordar no cerrar la plazuela, finalmente ésta se llevaría a cabo en 1955, siendo superiora Sor Dolores Martínez del Santísimo ${ }^{57}$.

Entre 1962 y 1968 se solicitan diversos arreglos a la Junta Nacional de Reconstrucción de Templos Parroquiales, ante la existencia de diversos desperfectos en el palacio y grietas en la torre de la iglesia que podrían amenazar la seguridad de las religiosas y alumnas $^{58}$. Sería en este momento cuando se procedería a desmontar la torre en su totalidad, que sería reconstruida a los pies de la iglesia en vez de hacerlo en su ubicación original a la derecha de la capilla mayor (Fig. 11). La razón de ese traslado cabría buscarla en el deseo de crear un enclave urbanístico con encanto pues, de hecho, también se procedería al saneamiento de la fachada, planteándose incluso la apertura de la portada de los pies que se encontraba cegada desde el siglo XVIII por la instalación del coro (algo que finalmente no se lleva a cabo). De hecho, por estos años se hermosearía la Plaza de San Pedro mediante la disposición de jardines y una fuente central.

Tras esta actuación, la Dirección General de Arquitectura intervendría en los tejados de la iglesia, lo cual nos sorprende puesto que generalmente este tipo de trabajos eran

${ }^{56}$ AHMU, Sesión permanente, 23-X-1944, fol, 281r.; 3-XI-1944, fol. 318r.; 6-XII-1944, fol. 341r. y 23-X-1944, fol. 281r.

${ }^{57}$ Ibídem, 20-V-1955, fol. 135r. El cierre presentaba 8 pilares de piedra sobre un basamento del mismo material, disponiéndose balaustres de hierro entre los pilares; con las obras de reconversión del antiguo edificio en un establecimiento hotelero llevadas a cabo en 2015 se eliminarían los pilares y la verja de hierro.

${ }^{58}$ AGA, Fondo Ministerio de la Vivienda - Junta Nacional de Reconstrucción de Templos Parroquiales, IDD (04)088.001, Caja 52/04191. Torre de la iglesia de las Carmelitas de la Caridad.

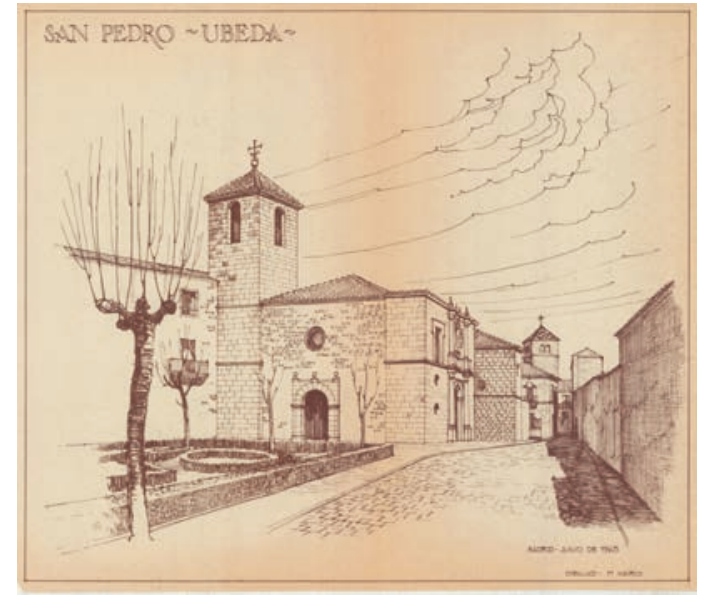

- Fig. 11. Ramiro Moya Blanco y Francisco PonsSorolla. Proyecto de restauración en la Iglesia de San Pedro. 1968. Ministerio de Educación, Cultura y Deporte. Archivo General de la Administración, Fondo Ministerio de la Vivienda, IDD (04)117.004, Caja 51/11908.

llevados a cabo por la Dirección General de Bellas Artes. Las razones parecen hallarse en el deseo de desarrollar una ruta turística por uno de los barrios más populares y pintorescos de Úbeda, tal y como declara el alcalde Jerónimo Garvín en una entrevista: "Las Direcciones Generales de Arquitectura y Bellas Artes han calado lo profundo de nuestra ciudad, hasta el extremo de ser ya realidades incuestionables la urbanización y creación del itinerario histórico-artístico que, partiendo de la Plaza de Vázquez de Molina, se internará en las calles de Santo Domingo, Puerta de Granada, San Lorenzo y Casa de las Torres hasta el Mirador del Alférez Rojas. La ejecución de esta ruta ascenderá a cinco millones de pesetas, en varias fases, y comenzará, dentro del plan de 1965, por la restauración de la iglesia de San Pedro y mejora del contorno en que está enclavada, con un presupuesto independiente al anterior, ascendiente a dos millones de pesetas" ${ }^{\prime \prime 9}$.

Si bien se iniciaron los estudios del mis$\mathrm{mo}^{60}$, dicho proyecto tardaría bastantes años

59 “El alcalde de Úbeda, D. Jerónimo Garvín Mesa, habla de las realizaciones y proyectos de la ciudad", Revista Vbeda, no 136, septiembre 1965, pp. 3-6.

${ }^{60}$ AGA, Fondo Ministerio de la Vivienda, IDD (04)117.004, Caja 51/12010. R. MOYA BLANCO, Úbeda. 

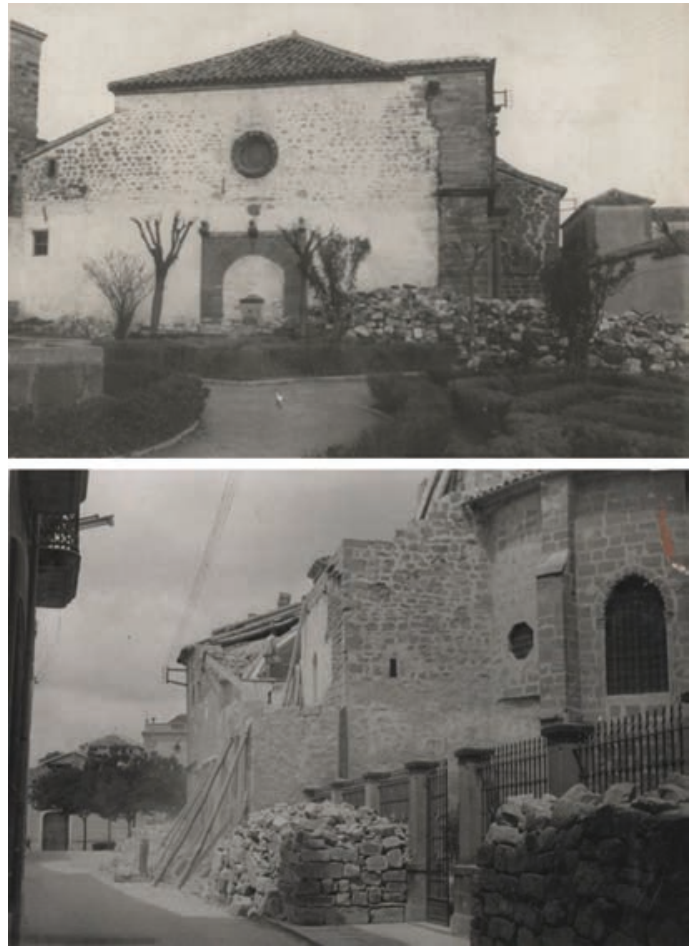

- Fig. 12. Intervención en la iglesia de San Pedro, Úbeda. 1964. Ministerio de Educación, Cultura y Deporte. Archivo General de la Administración, Fondo Ministerio de la Vivienda, IDD (04)117.004, Caja 51/11908.

en materializarse, teniendo que esperar a las actuaciones de Prieto-Moreno y Llopis Solbes para habilitar la Casa de las Torres como sede de la Escuela de Artes Aplicadas y Oficios Artísticos, así como la reforma global de las murallas y entorno de la Puerta de Granada llevada a cabo de forma independiente por Llopis para la recuperación completa de este entorno ${ }^{61}$.

En relación al proyecto de la iglesia de San Pedro, este se centraba en la consolidación y recuperación de la cubierta, así como de las cabezas de los muros en las que apoyaba, debido a que presentaba una forma desordenada como consecuencia de numerosas reformas y agregados; del mismo modo, su mal estado se incrementaba por los empujes

Puerta de Granada, Dirección General de Arquitectura Ordenación de Ciudades de Interés Artístico Nacional, 1967.

61 J.M. ALMANSA MORENO, "La restauración monumental en Úbeda...", pp. 71-86. generados en los muros, dando lugar a grandes humedades y goteras (a las que se sumaban los problemas que ocasionaba el pésimo estado del sistema de evacuación de aguas pluviales, así como el abandono y acumulación de tierras del predio colindante). La actuación consistió en desmontar la cubierta, sanear la parte alta de los muros, y volver a reconstruir la cubierta, limpiando y reparando del mismo modo las conducciones de agua pluviales (Fig. 12) ${ }^{62}$.

\section{CONCLUSIONES}

A través de este estudio hemos podido apreciar las diferentes intervenciones llevadas a cabo por la Dirección General de Arquitectura en algunos de los espacios urbanos más relevantes de la ciudad jiennense de Úbeda (Plaza Vázquez de Molina, Plaza del General Saro, Miradores del Salvador y Plaza de San Pedro), destinadas a mejorar la imagen de la ciudad y fomentar el desarrollo del turismo, una de las principales aspiraciones en la España del Franquismo.

A pesar de tratarse de intervenciones historicistas, grandilocuentes y folkloristas, estas actuaciones lograron cumplir con su objetivo principal como sería la llegada de capital extranjero, permitiendo consolidar la imagen de una nación en continuo desarrollo y progreso. Así, como resultado del binomio turismo-patrimonio, se lograría potenciar la imagen de Úbeda como símbolo y ejemplo del Renacimiento español, sentando las bases de su posterior desarrollo turístico (considerado en la actualidad como uno de los principales motores económicos de la ciudad).

62 AGA, Fondo Ministerio de la Vivienda, IDD (04)117.004, Caja 51/11908. F. PONS-SOROLLA Y ARNAU y R. MOYA BLANCO. Úbeda Proyecto de restauraciones en las cubiertas y cabezas de muros de la Iglesia de San Pedro, Dirección General de Arquitectura Ordenación de Ciudades de Interés Artístico Nacional, 1968. 


\section{BIBLIOGRAFÍA}

ALMANSA MORENO, J. M., “Hospitales y centros de beneficencia en la Úbeda decimonónica", Ilustración y libertades: revista de pensamiento e historia de las ideas, $\mathrm{n}^{-} 2$, 2011, pp. 81-108.

"Los espacios públicos en la Úbeda decimonónica", Boletín del Instituto de Estudios Giennenses, no 205, 2012, pp. 161-232.

“La restauración monumental en Úbeda durante los últimos años del franquismo: la obra de José Antonio Llopis Solbes", La Albolafia: Revista de Humanidades y Cultura, no 5, 2015, pp. 71-86.

CASTRO FERNÁNDEZ, B., “Restauración monumental y propaganda: perspectivas de intervención en España y Portugal", en P. GARCÍA CUETOS, E. ALMARCHA NUÑEZ-HERRADOR y A. HERNANDEZ MARTÍNEZ, Historia, restauración y reconstrucción monumental en la posguerra española, Madrid, 2012, pp. 157-190.

"De la ciudad. Ampliación del Parador del Condestable", Revista Vbeda, no 134, abril 1965, p. 28.

“De la Muy Noble y Muy Leal Ciudad. Preguntas al señor alcalde", Revista Vbeda, $\mathrm{n}^{-}$ 64, abril 1955, pp. 7-8.

“El alcalde de Úbeda, D. Jerónimo Garvín Mesa, habla de las realizaciones y proyectos de la ciudad", Revista Vbeda, no 136, septiembre 1965, pp. 3-6.

"El proyecto de urbanización y pavimentación de la Plaza del General Saro", Revista Vbeda, no 79, julio 1956, pp. 8-10.

GARCÍA DE PABLOS, R., “La reforma de la Plaza Vázquez de Molina", Revista Vbeda, no 4, 1950, pp. 8-9.

“Hablando con el Alcalde (entrevista a D. Pedro Sola Muñoz)", Revista Vbeda, no 1, enero 1950, pp. 10-11.

HERNÁNDEZ MARTÍNEZ, A. y CASTRO FERNÁNDEZ, B., "Patrimonio monumental y turismo. La ordenación de con- juntos monumentales en Aragón: el caso de Sos del Rey Católico (Zaragoza)", Erph: Revista electrónica de Patrimonio Histórico, $\mathrm{n}^{\mathrm{o}}$ 13, 2013, pp. 79-117.

JUAN MARTÍNEZ, L., Planeamiento y crecimiento urbanístico de Úbeda durante el Franquismo, Trabajo Fin de Máster dirigido por Ricardo Anguita Cantero y defendido en la Universidad de Granada, Granada, 2014 (inédito).

LATORRE BONACHERA, J. L., Catálogo Exposición Fotográfica "Úbeda, Patrimonio de la Humanidad. Ayer y Hoy", Úbeda, 2007.

MADRID DELGADO, M., "La estatua fusilada", Ideal, 10-IV-2010, p. 48.

MARÍN DE TERÁN, L., “Las transformaciones urbanas en Úbeda y Baeza durante el siglo XVI", en Úbeda en el siglo XVI, Úbeda, 2002, pp. 169-188.

MARTÍNEZ ELVIRA, J. R., “Tramas urbanas y vecindario en la Úbeda del Renacimiento", en Úbeda en el siglo XVI, Úbeda, 2002, pp. 189-218.

MARTÍNEZ MONEDERO, M., "El centro histórico: del olvido de posguerra a la escenografía" en P. GARCÍA CUETOS, E. ALMARCHA NUÑEZ-HERRADOR y A. HERNANDEZ MARTÍNEZ, Historia, restauración y reconstrucción monumental en la posguerra española, Madrid, 2012, pp. 223-246.

MARTÍNEZ TERCERO, E., "La recuperación del patrimonio español en la posguerra (1938-1958)", en J. MONJO CARRIÓ (dir.), Teoría e historia de la rehabilitación, Madrid, 1999, pp. 119-134.

MOLINA HIPÓLITO, J., “El Palacio del Ayuntamiento de Úbeda", Revista Vbeda, no 1 , enero 1950, p. 6.

MOLINA NAVARRETE, R., "Datos históricos del Colegio de las HH. Carmelitas de la Caridad de Úbeda", Revista Ibiut, no 4445, 1989, pp. 26-27.

MORENO MENDOZA, A., Úbeda renacentista, Madrid, 1993. 
“La Plaza Vázquez de Molina de Úbeda: nuevos datos para el análisis de su configuración urbanística", Espacio, tiempo y forma. Serie VII. Historia del Arte, no 15, 2002, pp. 71-94.

MUÑOZ COSME, A., "La documentación de restauración. Significado cultural", en Fuentes documentales para el estudio de la restauración de monumentos en España, Madrid, 1989, pp. 9-14.

PALMA CRESPO, M., Baeza restaurada. La restauración del patrimonio baezano en el siglo XX, Granada, 2015.

PASQUAU, J., "Una fuente monumental”, Revista Vbeda, no 8, agosto 1950, p. 1.

PONCE LLAVERO, P., “Una reunión de urbanistas, una exposición y las ciudades histórico-artísticas de nuestra provincia", Paisaje, marzo 1948, pp. 1261-1262.
ROMERO GALLARDO, A., "Apuntes y reflexiones en torno a la obra restauradora del arquitecto Francisco Prieto-Moreno y Pardo", E-rph: Revista electrónica de Patrimonio Histórico, nำ 7, 2010, pp. 1-23.

TORRES CAMACHO, J. N., “Turismo, patrimonio y desarrollo económico a través de las denominaciones geoturísticas en el Franquismo", en Impulso al Desarrollo Económico a través del Turismo. VIII Jornadas de Investigación en Turismo, Sevilla, 2006, pp. 257-272.

“Vbeda pregunta. Declaraciones del Sr. Alcalde D. Jerónimo Garvín", Revista Vbeda, no 129, mayo 1964, pp. 3-4.

VAÑÓ SILVESTRE, R., Protección legal de conjuntos histórico-artísticos. Su aplicación a Úbeda y Baeza, Jaén, 1980. 